Journal of Patient-Centered

7-19-2021

\title{
Cross-Sectional Analysis of Patient-Centered Language Use in Journals Publishing Research Focused on Heart Failure
}

\author{
Vivian Pham \\ Benjamin Greiner \\ Ryan Ottwell \\ Matt Vassar \\ Micah L. Hartwell
}

Follow this and additional works at: https://aah.org/jpcrr

Part of the Bioethics and Medical Ethics Commons, Cardiology Commons, Cardiovascular Diseases Commons, Health Services Research Commons, and the Internal Medicine Commons

\section{Recommended Citation}

Pham V, Greiner B, Ottwell R, Vassar M, Hartwell M. Cross-sectional analysis of patient-centered language use in journals publishing research focused on heart failure. J Patient Cent Res Rev. 2021;8:248-54. doi: $10.17294 / 2330-0698.1821$

Published quarterly by Midwest-based health system Advocate Aurora Health and indexed in PubMed Central, the Journal of Patient-Centered Research and Reviews (JPCRR) is an open access, peer-reviewed medical journal focused on disseminating scholarly works devoted to improving patient-centered care practices, health outcomes, and the patient experience. 


\title{
Cross-Sectional Analysis of Patient-Centered Language Use in Journals Publishing Research Focused on Heart Failure
}

\author{
Vivian Pham, DO, ${ }^{1,2}$ Benjamin Greiner, DO, MPH, ${ }^{3}$ Ryan Ottwell, DO, ${ }^{2,4}$ Matt Vassar, PhD, ${ }^{2}$ \\ Micah Hartwell, $\mathrm{PhD}^{5}$ \\ ${ }^{1}$ Department of Internal Medicine, University of Oklahoma Medical Center, Oklahoma City, OK; ${ }^{2}$ College of \\ Osteopathic Medicine, Oklahoma State University Center for Health Sciences, Tulsa, OK; ${ }^{3}$ Department of Internal \\ Medicine, University of Texas Medical Branch, Galveston, TX; ${ }^{4}$ Department of Internal Medicine, University of \\ Oklahoma-Tulsa School of Community Medicine, Tulsa, OK; ${ }^{5}$ Department of Psychiatry and Behavioral Sciences, \\ Oklahoma State University Center for Health Sciences, Tulsa, OK
}

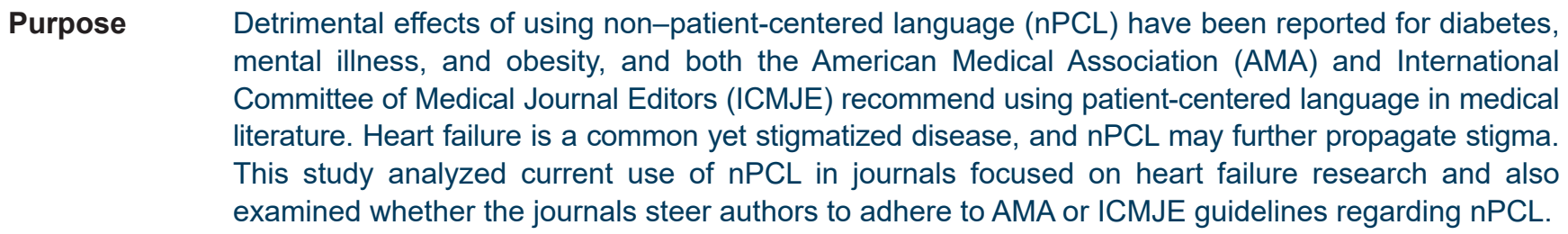

Methods Following systematic search of PubMed for heart failure-related articles published from May 1, 2018, to April 30, 2020, cross-sectional analysis was performed. Each selected article was inspected for an array of $\mathrm{nPCL}$ terms and frequency of $\mathrm{nPCL}$ usage. Chi-squared tests and multivariable logistic regressions were used to assess relationships between study characteristics and nPCL use.

Results Of the 195 articles fully analyzed, $108(55.4 \%)$ contained a nPCL term, the most frequently used being "heart failure patient" (78.7\%), "burden" (23.1\%), and "suffer" (15.7\%). Use of nPCL was disproportionately more common in original research articles $(63.5 \%)$ and less common in case reports (18.2\%). Articles that did not detail any treatment or intervention used the most $\mathrm{nPCL}(71.1 \%)$. No statistically significant association was found between a journal's impact factor and its adherence to AMA or ICMJE recommendations.

Conclusions $\mathrm{nPCL}$ is widely used in publications reporting on heart failure. We encourage authors and journals to reduce $\mathrm{nPCL}$ to help decrease the stigma patients with this disease often encounter. ( $J$ Patient Cent Res Rev. 2021;8:248-254.)

Keywords patient-centered language; heart failure; stigma; health research; publishing

$\mathrm{H}$ eart failure is one of the most deadly cardiovascular diseases, with a 30- to 60-day mortality rate of nearly $10 \%$ for both heart failure with reduced and preserved ejection fraction. ${ }^{1}$ It affects more than 26 million people worldwide, and the prevalence is increasing, a finding particularly concerning as many persons with heart failure are undertreated..$^{2,3}$ Savarese et al noted that although there have been significant advances in therapies for and prevention of heart failure, once a patient has heart failure, their mortality and morbidity rates remain unchanged. ${ }^{4}$ One contributing factor to a continued rate of morbidity and

Corresponding author: Vivian Pham, DO,

Oklahoma State University Center for Health Sciences, 1111

W. 17th St., Tulsa, OK 74107 (vivian.kv.pham@gmail.com) mortality could be due to the stigma associated with heart failure. Many of the risk factors for heart failure are highly stigmatized, including alcohol use disorder, cigarette use, and obesity, which may contribute to its undertreatment. ${ }^{5,6}$ Furthermore, people living with chronic illnesses are more likely to feel stigmatized and, as a result, access health care less and have poorer quality of life. ${ }^{7}$

Stigma is the social process of labeling, devaluing, and separating persons different from oneself and occurs at the interpersonal, intrapersonal, and system levels. ${ }^{8}$ Several types of stigma exist in health care - attitudes and behaviors, lack of awareness and skills, and therapeutic pessimism - all of which impact the quality of care stigmatized individuals receive. ${ }^{9}$ Another type of stigma includes defining patients by their diagnosis, for which the American Medical Association took an opposing stance 
in its recommendation to avoid labeling patients by their diagnosis and instead put the person before the diagnosis. ${ }^{10}$ Specifically, the AMA Manual of Style (AMAMS) urges authors to "avoid labeling (and thus equating) people with their disabilities or diseases (eg, the blind, schizophrenics, and epileptics). Instead, put the person first. Avoid describing persons as victims or with other emotional terms that suggest helplessness (afflicted with, suffering from, stricken with, maimed). Avoid euphemistic descriptions such as physically challenged or special." 10

This patient-centered approach to medicine was in accordance with that adopted by the Institute of Medicine for the respectful care of patients and their identities, needs, and values. ${ }^{11}$ AMAMS defines patient-centered language (PCL) as "a style of communication in which the person is listed first followed by descriptive terms, which avoids defining a person by his or her disease state and places emphasis on the person rather than the disease or disability." "Although PCL is frequently used in government and commercial agencies, its use in clinical settings may not be standard or translate over to research writing.

As peer-reviewed research represents the most accurate form of medical information, physician attitudes and behaviors are influenced by the information presented by and digested from these scientific journals. Thus, if stigmatized language is used in peer-reviewed publications, physicians may also continue this framing. Conversely, if PCL is predominantly used, patients may experience less stigma. To our knowledge, no study has analyzed the current use of PCL in research journals that publish studies focused on patients with heart failure. Thus, the primary objective of this work was to analyze the current use of PCL in such journals. Secondarily, this study examined whether the submission guidelines for the journals analyzed recommend authors adhere to either AMAMS or International Committee of Medical Journal Editors (ICMJE) recommendations addressing use of PCL.

\section{METHODS}

To explore the current state of PCL, we performed a cross-sectional analysis to systematically search PubMed for recent research related to heart failure. The PubMed search ranged from May 1, 2018, to April 30, 2020, and used the following search query:

"((heart failure) or heart failure[mesh terms]) or heart failures) or heart failures[mesh terms]) or weak heart) or weak heart[mesh terms]) or myocardial failure) or myocardial failure[mesh terms]) or myocardial insufficiency) or cardiac insufficiency) or cardiac insufficiency[mesh terms]) or cardiac failure) or cardiac failure[mesh terms]) or cardiac decompensation) or cardiac decompensation[mesh terms]) or cardiac incompetence) or cardiac decompensation) or cardiac insufficiency) or heart decompensation) or heart decompensation[mesh terms]) or heart incompetence) or heart insufficiency) or heart insufficiency[mesh terms]))) and ((humans[filter]) and (english[filter]))."

The resulting publications were saved in a comma-sortedvalue file and imported into Stata software (StataCorp LLC) for randomization, and the first 500 studies were selected for article screening and data extraction. Publications were included if they met the following criteria: 1) the study's patient population included patients with heart failure; 2) the study included only human participants; and 3) the study was available in English. For the purposes of this study, all peer-reviewed studies, including original investigations, brief reports, research letters, case reports, case series, and editorials, were eligible for inclusion. Publications that were either a reply to or commentary on another study were excluded.

Two extractors (V.P. and B.G.) were then trained on AMAMS guidelines for using PCL $^{10}$ with examples of person-first identification, devaluing, victimization, and euphemistic descriptions. During this training, a predefined list of non-patient-centered language (nPCL) terms were established in reference with the AMAMS guidelines. Following review of these guidelines, the extractors performed a blinded trial extraction of 30 publications, followed by unblinding and comparison of results to achieve consistency. The remaining 470 studies were screened and extracted in a masked, duplicate fashion. Each publication was searched for the following nPCL terms: "CHF patient," "Heart failure patient," "Heart failure subject," "burdened with," "dismal," "afflicted with," "sufferer," suffering with/from," and "problem with/from." Additional article data were extracted to include type of research conducted, whether the study was funded, the publishing journal's impact factor, whether the publishing journal recommends adherence to reporting guidelines, whether the journal recommends adherence to either AMAMS or ICMJE standards, and first and last author affiliations.

Assessment of the primary objective involved computing the percentage, frequency, and most common nPCL terms, which implied deviance from AMAMS's PCL guidelines. Secondarily, chi-squared tests and multivariable logistic regressions were used to assess differences and independent relationships between study characteristics and nPCL use. All analyses were performed using Stata 16.1.

\section{RESULTS}

The systematic search string returned a total of 9666 articles from 1570 journals. After including journals 


\section{Systematic Search:}

A systematic search of PubMed for CHF publications was conducted on $5 / 1 / 2020$, using a previously published search strategy between the dates $05 / 2018-04 / 2020$.

Journal Selection and Article Randomization: After downloading search returns, we used Stata 16.1 to exclude journals with less than 20 publications over heart failure during the prespecified time period. After journal exclusion, articles were randomized and 500 articles were selected for screening.

Article Eligibility: All peer-reviewed original search returns, including research letters, brief reports, and case reports (including published poster presentations and abstracts) with a focus on heart failure were retained. Articles were excluded if they were not available in English, did not include human subjects, or were not retrievable.

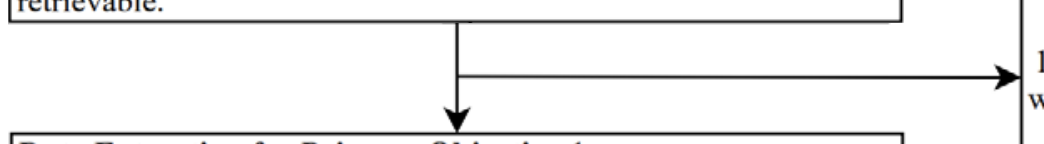

Data Extraction for Primary Objective 1:

Primary Objective: Articles were systematically searched for nonPCL terms, identified a priori, to evaluate article adherence to AMAMS guidelines. Terms/Phrases included:

"CHF patient," "Heart failure patient," "Heart failure subject," "burdened with," "dismal," "afflicted with," "sufferer," suffering with/from," and "problem with/from."

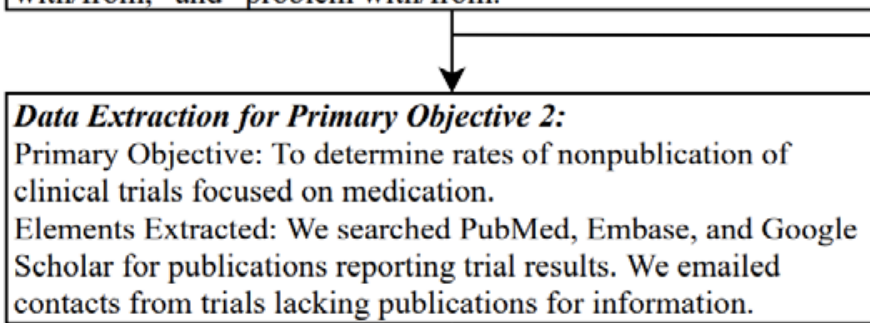

Primary Outcome:

Articles Retained:

195 articles met inclusion criteria . Excluded studies were either non-human subject, not in English, or not related to heart failure.

Journals Retained: criteria
103 journals were retained meeting initial inclusion 
with 20 or more citations, 103 journals were retained for article randomization and article selection. The selected 500 articles, from 96 journals, were then screened for inclusion; 305 articles were excluded due to not being heart failure-related, analyzing models other than humans, or being commentaries. This left 195 articles to investigate for adherence to PCL guidelines (Figure 1).

Of the 195 articles, 108 (55.4\%) contained one of the nPCL terms investigated, with the most frequently used terms being "heart failure patient" (78.7\%), "burden" (23.1\%), and "suffer" (15.7\%) (Figure 2). nPCL was prevalent in all types of research but was disproportionately more common in studies labeled as original research $(63.5 \%)$ while less common in case reports (18.2\%) (Table 1).

Studies that did not detail treatment or intervention of any kind utilized the most nPCL (71.1\%). Furthermore, there was no statically significant association found between a journal's impact factor and adherence to AMAMS or ICMJE recommendations (odds ratio: 1.04, 95\% CI: $1.00-1.07 ; \mathrm{P}=0.24)$.

\section{DISCUSSION}

Our study showed that nPCL language is common in publications focused on heart failure. Of the articles studied, more than half did not adhere to the guidelines of using PCL. The most frequent infraction was "HF patient," which is a failure to use person-first, as opposed to disease-first, language. New evidence has shown that stigmatized patients increasingly experience poorer routine care, lower quality of life, depression, and less health care utilization. ${ }^{13,14}$ Some contributing factors to patient feelings of stigma include the belief that intrapersonal health behaviors associated with heart failure, such as cigarette use and body habitus, are the only cause for the disease. ${ }^{15}$ Stigma can be internalized, externalized, and even anticipated, leading to health care barriers. ${ }^{16}$ Although the term "HF patient" seems mundane, studies have shown that patients with other chronic illnesses fare better when their conditions are referred to as a part of their life, not as a condition that defines the individual. ${ }^{17}$ For example, in regard to mental illness, "woman with bipolar disorder" is preferred over "bipolar patient."18

50

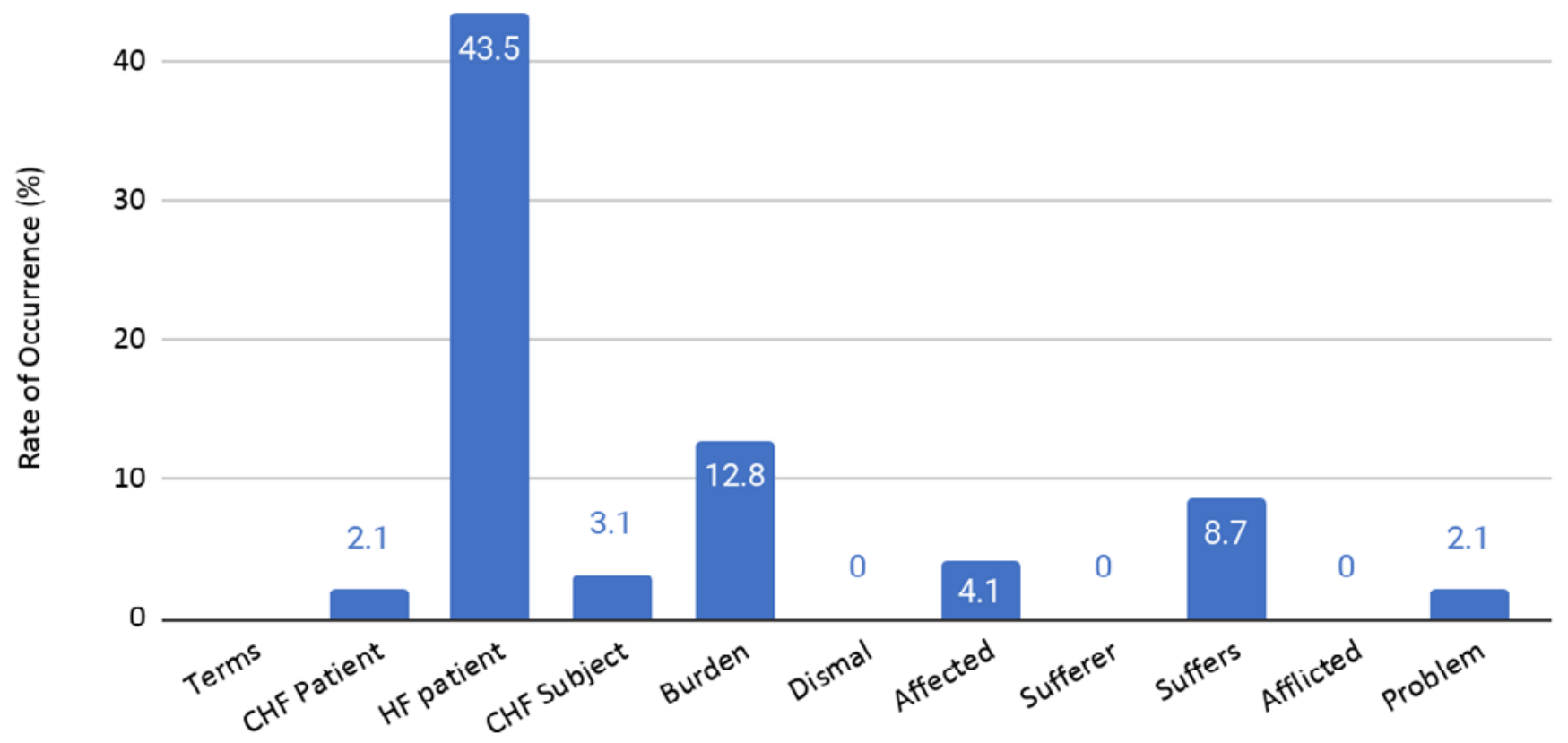

Figure 2. Frequency of non-patient-centered language terms found in heart failure (HF)-centric publications. CHF, congestive heart failure. 
Table 1. Characteristics of Articles With and Without Patient-Centered Language

\begin{tabular}{|c|c|c|c|c|}
\hline Characteristic & $\begin{array}{c}\text { No. of } \\
\text { articles } \\
(n=195)\end{array}$ & $\begin{array}{c}\text { Article } \\
\text { contained } \\
\mathrm{nPCL}(\mathrm{n}=108)\end{array}$ & $\begin{array}{c}\text { Article } \\
\text { adhered to } \\
\text { PCL }(n=87)\end{array}$ & $\begin{array}{c}\text { Statistical } \\
\text { analysis }\end{array}$ \\
\hline Type of article & & & & $P<0.001^{*}$ \\
\hline Original research & 145 & 92 & 53 & \\
\hline Case report & 22 & 4 & 18 & \\
\hline Editorial & 18 & 9 & 9 & \\
\hline Brief report & 8 & 3 & 5 & \\
\hline Research letter & 1 & 0 & 1 & \\
\hline Other & 1 & 0 & 1 & \\
\hline Type of research & & & & $X^{2}(4): 1.68 ; P=0.80$ \\
\hline Observational/Cross-sectional & 113 & 60 & 53 & \\
\hline Literature review & 44 & 25 & 19 & \\
\hline Editorial or case report & 15 & 9 & 6 & \\
\hline Clinical trial & 15 & 8 & 7 & \\
\hline Systematic review/Meta-analysis & 8 & 6 & 2 & \\
\hline Type of intervention & & & & $X^{2}(2): 10.47 ; P=0.005$ \\
\hline No treatment & 124 & 77 & 47 & \\
\hline Nonpharmacologic/Surgery & 43 & 23 & 20 & \\
\hline Drug/Pharmacologic treatment & 28 & 8 & 20 & \\
\hline \multicolumn{4}{|c|}{ Article adhered to reporting guidelines (CONSORT, STROBE, PRISMA, other) } & $P=0.19^{*}$ \\
\hline Yes & 10 & 8 & 2 & \\
\hline No & 185 & 100 & 85 & \\
\hline Funding & & & & $X^{2}(1): 1.96 ; P=0.16$ \\
\hline Yes & 71 & 44 & 27 & \\
\hline
\end{tabular}

${ }^{*} P$-value calculated using Fisher's exact test.

nPCL, non-patient-centered language; PCL, patient-centered language.

The Association for Medical Education and Research in Substance Abuse endorses that language can affect how an individual thinks about themselves and their own ability to change. ${ }^{19}$ When compared to patients with myocardial infarction, it was found that patients with heart failure often are interviewed differently about acute symptoms, are less likely questioned about circumstances surrounding their acute episode, and as a result often delay their presentation to the hospital. The delay in health care for patients with heart failure compared to those with myocardial infarctions is mainly due to lack of communication, which could be improved with decreased stigma toward patients with heart failure. ${ }^{20}$ Furthermore, if $\mathrm{nPCL}$ is read, imprinted, and used in the medical record, it can be further propagated from one clinician to another, thereby further impairing health care quality for stigmatized patients. ${ }^{21}$ The translation of stigma into the record is particularly concerning with the dawn of new medical technology and open patient access to notes in their electronic medical records.

Considering the high rate of readmission and mortality in patients with heart failure, which is partly due to poor access to health care and indirectly to stigma, ${ }^{22}$ it is imperative that physicians, hospital organizations, and medical research journals make greater efforts toward removing stigma in those treated for heart failure. It has been found that the reduction of stigma in health care can lead to positive attitude changes in patients, knowledge improvement of chronic diseases, and long-term changes in behavior of patients. ${ }^{23}$ For example, in patients with HIV, a highly stigmatized area in medicine, stigma can lead to obstacles for prevention efforts, psychological distress, inhibit treatment adherence, and act as a barrier 
Table 2. Examples of Person-First Language to Reduce Stigma

\begin{tabular}{c|c}
\hline Instead of this: & Use this: \\
\hline CHF (or HF) patient & Patient with CHF \\
Heart failure patient & $\begin{array}{c}\text { Patient with heart failure } \\
\text { Patient with heart failure }\end{array}$ \\
\hline Dismal chance of survival & $\begin{array}{c}\text { Reduced chance of survival } \\
\text { Patient diagnosed with } \\
\text { heart failure }\end{array}$ \\
\hline $\begin{array}{c}\text { Affected by heart failure } \\
\text { heart failure }\end{array}$ & $\begin{array}{c}\text { Patient living with } \\
\text { heart failure }\end{array}$ \\
Afflicted by heart failure & $\begin{array}{c}\text { Patient diagnosed with } \\
\text { heart failure }\end{array}$ \\
Heart failure problem & Patient with heart failure \\
\hline
\end{tabular}

toward treatment adherence. ${ }^{24}$ Vice versa, other studies detailing efforts to reduce stigma have led to increased testing, better adherence to treatment, improved quality of life, and even changed quality of care and interactions between providers and patients. ${ }^{25}$

Some methods for reducing stigma secondary to nPCL use include revising journal submission guidelines and developing medical school curriculum to incorporate appropriate PCL. Furthermore, the American Diabetes Association has adjudicated for the use of PCL in its most recent Standards of Medical Care in Diabetes statement; ${ }^{26}$ however, to date, no cardiovascular or heart failure society has published a stance on this form of language use. Therefore, we recommend the American Heart Association, American College of Cardiology, and other organizations promoting care for patients with heart failure develop new guidelines for the use of appropriate PCL and for researchers and journals to adhere to them stringently. For physicians and other health care providers, we suggest that it become common practice to use PCL when referring to patients (Table 2).

\section{Limitations}

Our study had notable limitations. First, nPCL was independently extracted by the researchers and, thus, it is possible that human error affected the results. However, this effect was minimized through the use of previously validated training methods for each extractor prior to data collection. Second, we only collected nPCL verbiage from a sample of published literature; thus, the true use of this language may be greater or lesser than our findings. Conversely, the strengths of our study include the robust methodology and randomized sampling techniques.

\section{CONCLUSIONS}

Findings from this study suggest that although there are guidelines in place regarding avoiding the use of nonpatient-centered language in scientific writing, it remains widespread in the scientific community. The use of nPCL in regard to heart failure could lead to stigma that may adversely affect patient outcomes. Further guideline improvements, redefinition of physicians' mental framework of patients with heart failure, and research on the negative impacts of heart failure stigma in health care is recommended.

\section{Patient-Friendly Recap}

- Updated scientific writing guides recommend authors use person-first language (for example, "patient with cancer") as opposed to defining people by their disease ("cancer patient").

- The authors reviewed published literature on heart failure to gauge if this particular chronic disease, for which patients have encountered stigma by health care providers, is being appropriately reported by medical journals.

- More than half of the analyzed articles failed to adhere to the predefined patient-centered language standards. Some described patients in their studies as "burdened" or "suffering."

- Researchers, clinicians, and journals are encouraged to use patient-centered language in their scientific publications to avoid spreading stigmatization of patients.

\section{Author Contributions}

Study design: Grenier, Ottwell, Vassar, Hartwell. Data acquisition or analysis: Pham, Grenier, Ottwell, Hartwell. Manuscript drafting: Pham, Grenier, Ottwell. Critical revision: Pham, Ottwell.

\section{Conflicts of Interest}

None.

\section{References}

1. O'Connor CM, Abraham WT, Albert NM, et al. Predictors of mortality after discharge in patients hospitalized with heart failure: an analysis from the Organized Program to Initiate Lifesaving Treatment in Hospitalized Patients with Heart Failure (OPTIMIZE-HF). Am Heart J. 2008;156:662-73. CrossRef

2. Ponikowski P, Anker SD, AlHabib KF, et al. Heart failure: preventing disease and death worldwide. ESC Heart Fail. 2014;1:4-25. CrossRef

3. Moscova L, Leblanc F, Cittee J, et al. Changes over time in attitudes towards the management of older patients with heart failure by general practitioners: a qualitative study. Fam Pract. 2020;37:110-7. $\underline{\text { CrossRef }}$ 
4. Savarese G, Lund LH. Global public health burden of heart failure. Card Fail Rev. 2017;3:7-11. CrossRef

5. Puhl RM, Heuer CA. Obesity stigma: important considerations for public health. Am J Public Health. 2010;100:1019-28. CrossRef

6. Pachankis JE, Hatzenbuehler ML, Starks TJ. The influence of structural stigma and rejection sensitivity on young sexual minority men's daily tobacco and alcohol use. Soc Sci Med. 2014;103:67-75. CrossRef

7. Earnshaw VA, Quinn DM. The impact of stigma in healthcare on people living with chronic illnesses. J Health Psychol. 2012;17:157-68. CrossRef

8. Link BG, Phelan JC. Conceptualizing stigma. Ann Rev Sociol. 2001;27:363-85. CrossRef

9. Knaak S, Mantler E, Szeto A. Mental illness-related stigma in healthcare: barriers to access and care and evidence-based solutions. Healthc Manage Forum. 2017;30:111-6. CrossRef

10. Christiansen S, Iverson C, Flanagin A, et al. AMA Manual of Style: A Guide for Authors and Editors, 11th Edition. Oxford University Press; 2020.

11. Institute of Medicine (US) Committee on Quality of Health Care in America. Crossing the Quality Chasm: A New Health System for the 21st Century. National Academies Press (US); 2001. CrossRef

12. Frey $\mathrm{T}$, Young RK. Correct and preferred usage. In: Christiansen S, Iverson C, Flanagin A, et al. AMA Manual of Style: A Guide for Authors and Editors, 11th Edition. Oxford University Press; 2020. Accessed July 9, 2021. https://www.amamanualofstyle. com/view/10.1093/jama/9780190246556.001.0001/med9780190246556-chapter-11-div2-26

13. Phelan SM, Burgess DJ, Yeazel MW, Hellerstedt WL, Griffin JM, van Ryn M. Impact of weight bias and stigma on quality of care and outcomes for patients with obesity. Obes Rev. 2015;16:319-26. CrossRef

14. Chin ED, Armstrong D. Anticipated stigma and healthcare utilization in COPD and neurological disorders. Appl Nurs Res. 2019;45:63-8. CrossRef

15. Johnson JL, Campbell AC, Bowers M, Nichol AM. Understanding the social consequences of chronic obstructive pulmonary disease: the effects of stigma and gender. Proc Am Thorac Soc. 2007;4:680-2. CrossRef
16. Earnshaw VA, Quinn DM. The impact of stigma in healthcare on people living with chronic illnesses. $J$ Health Psychol. 2012;17:157-68. CrossRef

17. Crocker AF, Smith SN. Person-first language: Are we practicing what we preach? J Multidiscip Healthc. 2019;12:125-9. CrossRef

18. Broyles LM, Binswanger IA, Jenkins JA, et al. Confronting inadvertent stigma and pejorative language in addiction scholarship: a recognition and response. Subst Abus. 2014;35:217-21. CrossRef

19. Kelly JF, Westerhoff CM. Does it matter how we refer to individuals with substance-related conditions? A randomized study of two commonly used terms. Int J Drug Policy. 2010;21:202-7. CrossRef

20. Goldberg RJ, Goldberg JH, Pruell S, et al. Delays in seeking medical care in hospitalized patients with decompensated heart failure. Am J Med. 2008;121:212-8. CrossRef

21. Goddu AP, O'Conor KJ, Lanzkron S, et al. Do words matter? Stigmatizing language and the transmission of bias in the medical record. J Gen Intern Med. 2018;33:685-91. CrossRef

22. Desai AS, Stevenson LW. Rehospitalization for heart failure: predict or prevent? Circulation. 2012;126:501-6. CrossRef

23. Thornicroft G, Mehta N, Clement S, et al. Evidence for effective interventions to reduce mental-health-related stigma and discrimination. Lancet. 2016;387:1123-32. CrossRef

24. Stutterheim SE, Pryor JB, Bos AER, Hoogendijk R, Muris P, Schaalma HP. HIV-related stigma and psychological distress: the harmful effects of specific stigma manifestations in various social settings. AIDS. 2009;23:2353-7. CrossRef

25. Pulerwitz, J, Michaelis A, Weiss E, Brown L, Mahendra V. Reducing HIV-related stigma: lessons learned from Horizons research and programs. Public Health Rep. 2010;125:272-81. CrossRef

26. American Diabetes Association. 4. Comprehensive medical evaluation and assessment of comorbidities: Standards of Medical Care in Diabetes-2019. Diabetes Care. 2019;42(Suppl 1):S34-S45. CrossRef

(C) 2021 Advocate Aurora Health, Inc. 